Article

\title{
The Cardiotoxicity Induced by Arsenic Trioxide is Alleviated by Salvianolic Acid A via Maintaining Calcium Homeostasis and Inhibiting Endoplasmic Reticulum Stress
}

\author{
Ruiying Wang ${ }^{1,2,3,4,+}$, Jingyi Zhang ${ }^{1,2,3,4,+}$, Shan Wang ${ }^{1,2,3,4} \oplus$, Min Wang ${ }^{1,2,3,4}$, \\ Tianyuan Ye ${ }^{1,2,3,4} \mathbb{D}$, Yuyang Du ${ }^{1,2,3,4}$, Xueheng Xie ${ }^{5}$, Jingxue Ye ${ }^{1,2,3,4, *}$, \\ Guibo Sun ${ }^{1,2,3,4, *}$ and Xiaobo Sun $1,2,3,4, *$ \\ 1 Beijing Key Laboratory of Innovative Drug Discovery of Traditional Chinese Medicine (Natural Medicine) \\ and Translational Medicine, Institute of Medicinal Plant Development, Peking Union Medical College and \\ Chinese Academy of Medical Sciences, Beijing 100193, China; wangruiying2233@yeah.net (R.W.); \\ zhangjingyi707@126.com (J.Z.); wangshan19890625@126.com (S.W.); lily_12506053@163.com (M.W.); \\ yetianyuan2013@163.com (T.Y.); du_yuyang@sina.cn (Y.D.) \\ 2 Key Laboratory of Bioactive Substances and Resource Utilization of Chinese Herbal Medicine, \\ Ministry of Education, Beijing 100193, China \\ 3 Key Laboratory of Efficacy Evaluation of Chinese Medicine against Glycolipid Metabolic Disorders, \\ State Administration of Traditional Chinese Medicine, Beijing 100193, China \\ 4 Zhongguancun Open Laboratory of the Research and Development of Natural Medicine and Health \\ Products, Beijing 100193, China \\ 5 Harbin University of Commerce, Harbin 150028, China; xiexueheng@163.com \\ * Correspondence: yejingxue2002@126.com (J.Y.); gbsun@implad.ac.cn (G.S.); xbsun@implad.ac.cn (X.S.); \\ Tel.: +86-010-5783-3467 (J.Y.); +86-010-5783-3220 (G.S.); +86-010-5783-3013 (X.S.) \\ + These authors contributed equally to this paper.
}

Received: 5 January 2019; Accepted: 30 January 2019; Published: 2 February 2019

Abstract: Arsenic trioxide (ATO) has been verified as a breakthrough with respect to the management of acute promyelocytic leukemia (APL) in recent decades but associated with some serious adverse phenomena, particularly cardiac functional abnormalities. Salvianolic acid A (Sal A) is a major effective component in treating ATO-induced cardiotoxicity. Therefore, the objective of our study was to assess whether Sal A had protective effects by the regulation of calcium homeostasis and endoplasmic reticulum (ER) stress. For the in vivo study, BALB/c mice were treated with ATO and/or Sal A via daily tail vein injections for two weeks. For the in vitro study, we detected the effects of ATO and/or Sal A in real time using adult rat ventricular myocytes (ARVMs) and an IonOptix MyoCam system. Our results showed that Sal A pretreatment alleviated cardiac dysfunction and $\mathrm{Ca}^{2+}$ overload induced by ATO in vivo and vitro. Moreover, Sal A increased sarcoplasmic reticulum (SR) $\mathrm{Ca}^{2+}$-ATPase (SERCA) activity and expression, alleviated $\left[\mathrm{Ca}^{2+}\right] \mathrm{ER}$ depletion, and decreased ER stress-related protein expression. Sal A protects the heart from ATO-induced injury and its administration correlates with the modulation of SERCA, the recovery of $\mathrm{Ca}^{2+}$ homeostasis, and the down-regulation of ER stress-mediated apoptosis.

Keywords: salvianolic acid A; arsenic trioxide; cardiotoxicity; calcium overload; endoplasmic reticulum stress

\section{Introduction}

Arsenic-containing compounds have been used as medicines to treat multiple diseases, including cancer, syphilis and malaria, for more than 2000 years [1]. However, these compounds were not used 
worldwide until the Food and Drug Administration (FDA) approved arsenic trioxide (ATO) for the treatment of relapsed and refractory acute promyelocytic leukemia (APL) [2,3]. The clinical application of ATO is hampered by cardiac toxicity manifesting as QT interval prolongation, torsade de pointes (TdP) or even sudden cardiac death $[4,5]$.

The mechanisms underlying ATO-induced cardiotoxicity are complex and include mainly oxidative stress and calcium overload [6,7]. Several studies have shown that these two mechanisms affect each other, as the excessive production of ROS can inhibit the uptake of $\mathrm{Ca}^{2+}$ by the release of $\mathrm{Ca}^{2+}$ from the endoplasmic reticulum/sarcoplasmic reticulum (ER/SR), resulting in calcium homeostasis imbalances [8,9]. As previously described in our studies, ATO contributes to $\mathrm{Ca}^{2+}$ overload and ROS overproduction, which eventually leads to ER stress and oxidative stress-mediated cardiomyocyte apoptosis [10]. Thus, regulation of calcium homeostasis and inhibition of ROS overproduction may protect from ATO-induced myocardial injury.

Salvia miltiorrhiza Bunge (also known as Danshen) is widely used in China to treat cardiovascular diseases. Salvianolic acid A (Sal A; Figure 1) is the main effective, water-soluble constituent of S. miltiorrhiza, a well-known Chinese traditional herbal medicine. Sal A is able to increase antioxidant enzyme activity, suppress ROS overproduction, and attenuate ATO-induced cardiac injury in $\mathrm{H} 9 \mathrm{c} 2$ cells as previously disclosed [11]. It has also been reported that Sal A inhibits $\mathrm{I}_{\mathrm{CaL}}$ dose-dependently, suggesting that the $\mathrm{Ca}^{2+}$-antagonizing effect of Sal A is beneficial with respect to the treatment of myocardial ischemia-reperfusion injury [12]. Moreover, Sal A attenuated ER stress by preventing calcium release in liver LO2 cells [13]. These findings have prompted us to study whether the cardioprotective effects of Sal A are relevant with regulation of calcium homeostasis imbalances and subsequent ER stress-related apoptosis.

Attenuating ATO-induced toxic effects in the heart may have a tremendous impact on anti-cancer treatment. Therefore, this study aimed to demonstrate whether Sal A improves the cardiac contractile functional abnormalities induced by ATO and to investigate the potential effects of Sal A on calcium homeostasis imbalances and ER stress.

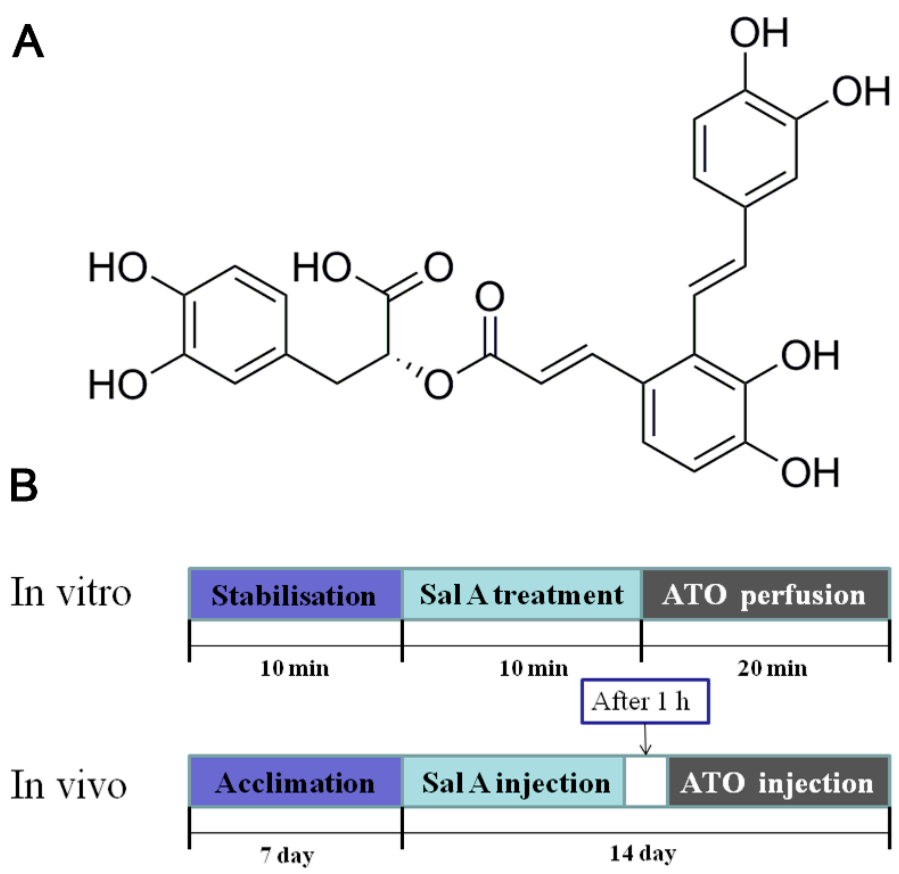

Figure 1. (A) Molecular structure of salvianolic acid A (Sal A). (B) The in vivo and in vitro experimental designs. ATO, arsenic trioxide. 


\section{Results}

\subsection{Effects of Sal A on Cardiac Function}

The experiment evaluated the effect of Sal A through an in vivo mouse model of ATO-induced cardiotoxicity. As grouped, M-mode echocardiography was used to examine the effects (Figure 2A). Both the ejection fraction (EF) and the fractional shortening (FS) were significantly decreased after mice were treated with ATO alone but were dramatically increased after mice were administered the two drugs compared with mice of the control group (Figure 2B). However, systole and diastole functions of the left ventricular showed no significant differences among the four groups.

A

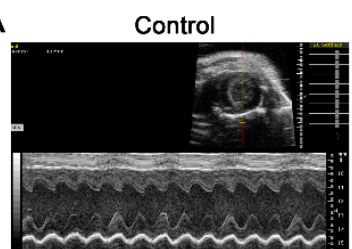

B

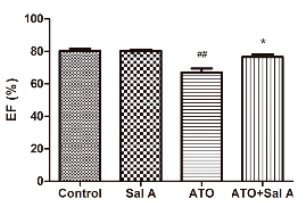

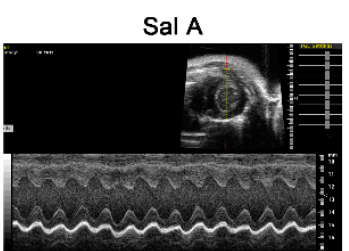

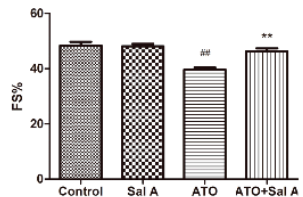

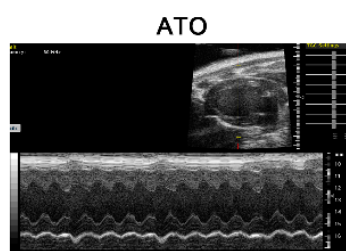

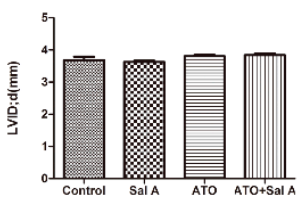

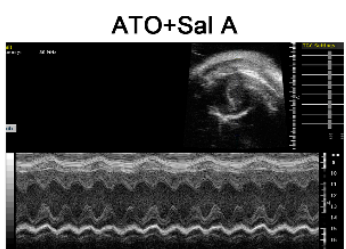

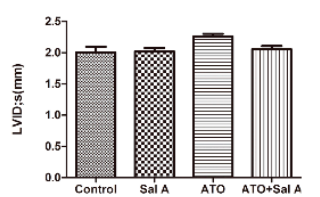

Figure 2. Sal A ameliorated left ventricular functions after ATO treatment. After mice were treated with saline or ATO with/without Sal A pretreatment for two weeks, echocardiography was finished. (A) Images of M-mode echocardiograms; (B) echocardiography indices, expressed as the mean \pm SD. EF, ejection fraction; FS, fractional shortening; LVIDd, left ventricular internal diameter in diastole; LVIDs, left ventricular internal diameter in systole. ${ }^{\# \#} p<0.01$ vs. control; ${ }^{*} p<0.05$ vs. ATO group; ** $p<0.01$ vs. ATO group.

\subsection{Sal A Prevents ATO-Induced Myocardial Damage}

The overall distribution of myocardial damage at the light microscopy level is shown in Figure 3A. The hearts after ATO treatment by hematoxylin-eosin (HE) staining indicated myofibrillar loss, cardiomyocyte necrosis and structural abnormalities, but these abnormalities were partially prevented by Sal A treatment. The Sal A-treated group showed no difference compared to the control group.

The serum levels of cardiac enzymes, including creatine kinase (CK), aspartate aminotransferase (AST), and lactate dehydrogenase (LDH) were measured to reflect myocardial damage [14]. The $\mathrm{ATO}+$ Sal A group significantly alleviated the increases of cardiac enzyme levels induced by ATO, while Sal A treatment alone did not induce clear changes in cardiac enzyme levels compared with the control group (Figure 3B).

\subsection{Sal A Improves Antioxidant Enzyme Activities}

In contrast with the control group, catalase (CAT), glutathione peroxidase (GSH-PX) and superoxide dismutase (SOD) activity levels in the ATO group were decreased. However, this decrease was reversed by the ATO + Sal A group, as shown in Figure 3C. These findings illustrated that Sal A significantly improves antioxidant activity of cardiomyocytes against oxidative stress induced by ATO. 
A

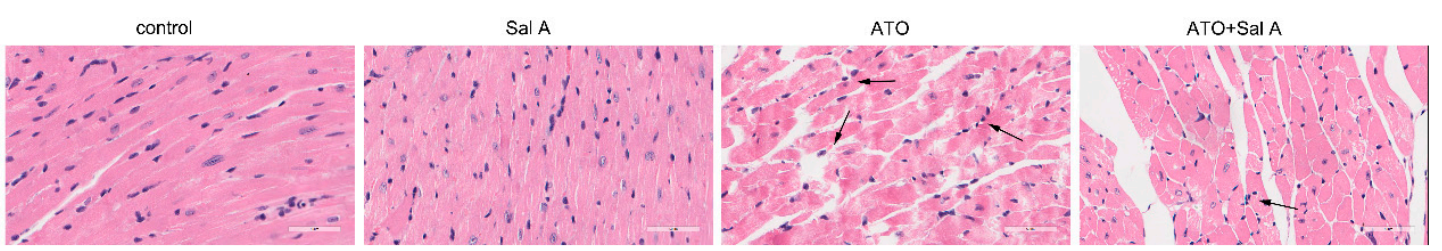

B
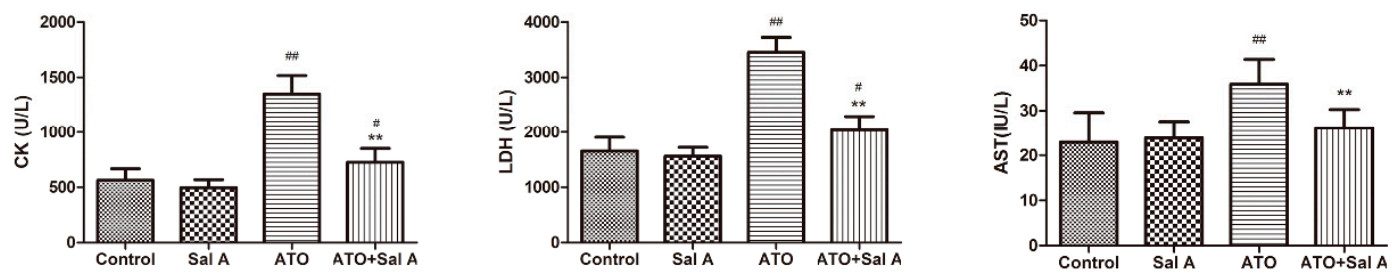

C
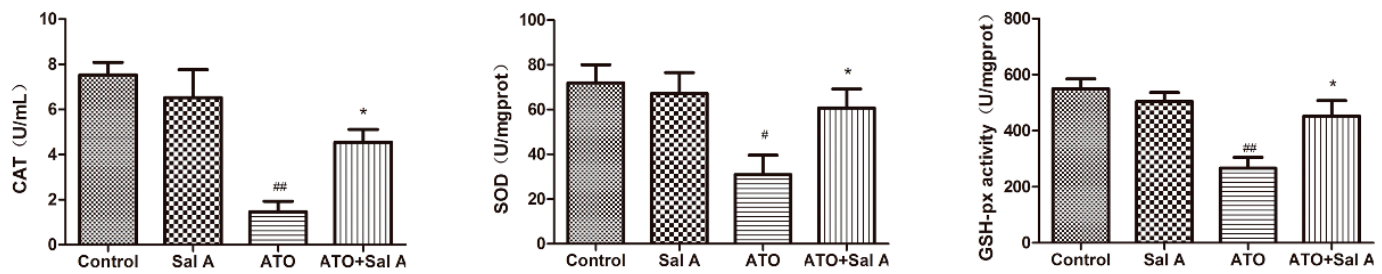

Figure 3. Sal A alleviated ATO-induced myocardial injury in mice hearts. (A) Hematoxylin-eosin (HE) staining showed the effects of Sal A on histological changes of mouse hearts. The scale bar is $50 \mu \mathrm{m}$. (B) Effects of Sal A on creatine kinase (CK), lactate dehydrogenase (LDH), and aspartate aminotransferase (AST) activity in plasma, and (C) effects of Sal A on catalase (CAT), superoxide dismutase (SOD), and glutathione peroxidase (GSH-PX) activity in plasma, expressed as the mean $\pm \mathrm{SD}(n=15$ per group). ${ }^{\#} p<0.05$ vs. control; ${ }^{\# \#} p<0.01$ vs. control; ${ }^{*} p<0.05$ vs. ATO group; ${ }^{* *} p<0.01$ vs. ATO group.

\subsection{Effects of Sal A on Cardiomyocyte Contractile Function in ARVMs after ATO Treatment}

Adult rat ventricular myocytes (ARVMs) were perfused with $1 \mu \mathrm{M}$ Sal A for $10 \mathrm{~min}$ before being treated with $100 \mu \mathrm{M}$ ATO for $20 \mathrm{~min}$ to explore whether the injuries of cardiomyocyte contractile function induced-ATO were alleviated by Sal A. As shown in Figure 4, Sal A treatment did not change six indicators of cardiomyocyte function compared with control treatment. Treatment with $\mathrm{ATO}+\mathrm{Sal}$ A displayed a normal sarcomere-contraction amplitude (Figure 4B), maximal shortening velocity $(+\mathrm{dL} / \mathrm{dt}$ ) (Figure $4 \mathrm{D})$, time to $90 \%$ relengthening (TR90) (Figure $4 \mathrm{E}$ ), and time to peak shortening (TPS) (Figure 4F), whereas the group treated with ATO displayed a significantly increased sarcomere-shortening amplitude, $\pm \mathrm{dL} / \mathrm{dt}$, TR90 and TPS compared with the groups treated with other agents. The above results show that ATO treatment severely impaired cardiomyocyte contractile function and that this impairment was eliminated by Sal A treatment. 

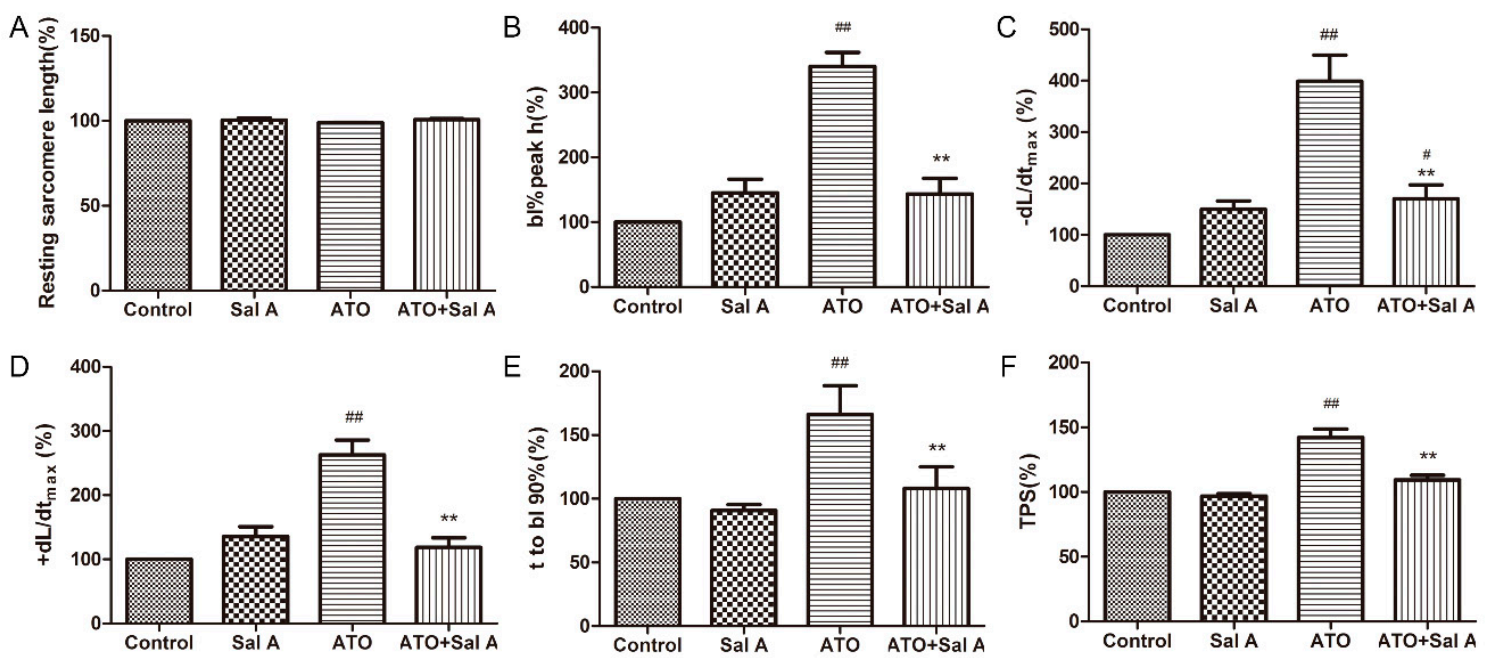

Figure 4. Sal A enhanced contractile function of adult rat ventricular myocytes (ARVMs) after ATO treatment. (A) Resting sarcomere length. (B) Sarcomere-shortening amplitude. (C) maximal relengthening velocity ( $-\mathrm{dL} / \mathrm{dtmax})$. (D) maximal shortening velocity ( $+\mathrm{dL} / \mathrm{dtmax}$ ). (E) time to $90 \%$ relengthening. (F) time to peak shortening (TPS). Data are expressed as the mean $\pm \operatorname{SD}\left(n=30-40\right.$ per group), ${ }^{*} p<0.05$ vs. control, ${ }^{\# \#} p<0.01$ vs. control, ${ }^{* *} p<0.01$ vs. ATO.

\subsection{Effects of Sal A on Intracellular $\mathrm{Ca}^{2+}$ Transients in ARVMs after ATO Treatment}

In our subsequent experiments, $\mathrm{Ca}^{2+}$ transients were detected by intracellular fura-2 fluorescence. Similar to the results of the previous study [15], the results of this study showed that ATO treatment induced an increase in the resting $\mathrm{Ca}^{2+}$ ratio, $\mathrm{Ca}^{2+}$ transient amplitudes, $\pm \mathrm{d}\left[\mathrm{Ca}^{2+}\right] / \mathrm{dtmax}$, the time to $50 \%$ peak $\left[\mathrm{Ca}^{2+}\right]_{\mathrm{i}}$, and the $\left[\mathrm{Ca}^{2+}\right]_{\mathrm{i}}$ transient decay rate compared with the control group in Figure S1 and Figure S2. Sal A treatment remarkably decreased these indices in the ATO + Sal A group compared with the ATO group (Figure 5A-F). Our data also showed that calcium homeostasis imbalance induced by ATO in ARVMs was greatly ameliorated by Sal A.
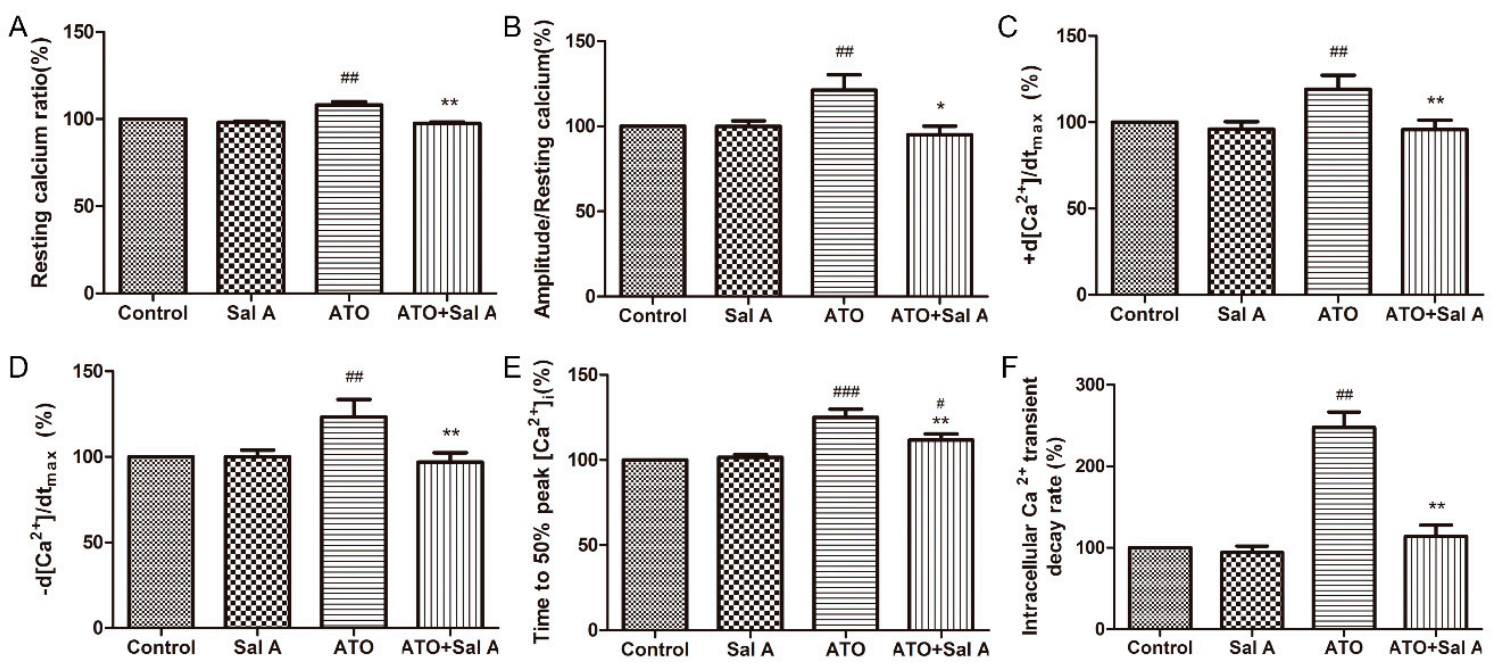

Figure 5. Sal A regulated intracellular $\mathrm{Ca}^{2+}$ transients in ARVMs after ATO treatment. (A) Resting $\mathrm{Ca}^{2+}$ ratio. (B) Amplitude/resting calcium ratio. (C) Maximal $\mathrm{Ca}^{2+}$ shortening velocity $\left(+\mathrm{d}\left[\mathrm{Ca}^{2+}\right] / \mathrm{dtmax}\right)$. (D) Maximal $\mathrm{Ca}^{2+}$ relaxation velocity $\left(-\mathrm{d}\left[\mathrm{Ca}^{2+}\right] / \mathrm{dtmax}\right)$. (E) Time to $50 \%$ peak $\left[\mathrm{Ca}^{2+}\right]_{\mathrm{i}}$. (F) Intracellular $\mathrm{Ca}^{2+}$ transient decay rate. Data are expressed as the mean $\pm \mathrm{SD}\left(n=30-40\right.$ per group), ${ }^{*} p<0.05 \mathrm{vs}$. control, ${ }^{\# \#} p<0.01$ vs. control, ${ }^{*} p<0.05$ vs. ATO, ${ }^{* *} p<0.01$ vs. ATO. 


\subsection{Effects of Sal A on sarco endoplasmic reticulum $\mathrm{Ca}^{2+}$-ATPase (SERCA) Activity}

SERCA2a regulates $\mathrm{Ca}^{2+}$ in the intracellular by affecting SR $\mathrm{Ca}^{2+}$ intake. Intracellular $\mathrm{Ca}^{2+}$ overload and cardiac myocyte dysfunction can be regulated by reducing SERCA expression and activity [16]. SERCA activity of ARVMs and mice heart tissue were detected respectively. ATO treatment reduced SERCA activity compared with the control treatment, whereas Sal A treatment significantly reversed the effects of ATO on SERCA activity both in ARVMs and mice heart tissue in Figure 6 . These data suggest that Sal A enhanced SERCA activity so reduced cardiotoxicity induced by ATO.

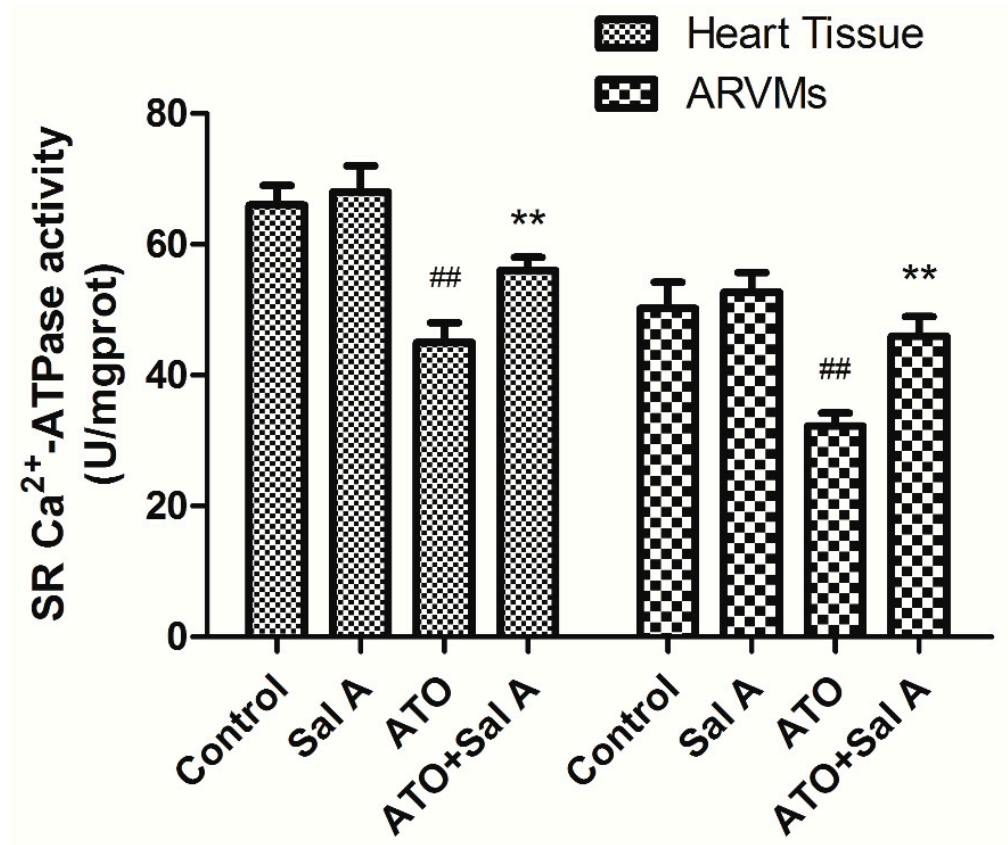

Figure 6. Sal A enhanced SERCA activity in ARVMs and mice heart tissue after ATO treatment. Data are expressed as the mean $\pm \mathrm{SD}{ }^{\# \#} p<0.01$ vs. control, ${ }^{* *} p<0.01$ vs. ATO.

\subsection{Effects of Sal A on $\mathrm{Ca}^{2+}$ and ER Stress-Related Protein Expression Levels after ATO Treatment}

The results showed the regulatory effects of Sal A-treatment on $\mathrm{Ca}^{2+}$-related protein expression in heart tissue and ARVMs. As shown in Figure 7, SERCA2a activity levels and phospholamban (PLB) phosphorylation levels decreased significantly after ATO treatment compared with the control treatment. However, Sal A treatment prevented the decrease. These results indicate that Sal A regulates $\mathrm{Ca}^{2+}$-related protein expression levels to prevent calcium overload induced by ATO.

Several studies have confirmed that calcium steady-state imbalances cause calcium overload, which ultimately triggers ER stress [17]. Thus, we examined the expression of ER stress and apoptosis-involved proteins. As shown in Figure 7, expression levels of glucose-regulated protein 78 (GRP78), an ER stress response marker, were markedly higher after ATO treatment than after the control treatment. The same patterns of change were observed for c-Jun NH2-terminal kinase (JNK), C/EBP-homologous protein (CHOP) and caspase-12. However, Sal A significantly attenuated ATO-induced overexpression of ER stress-related proteins in both ARVMs and mice heart tissue. Collectively, the data showed that ER stress was activated after ATO treatment. Most importantly, these results also indicated that Sal A treatment significantly inhibited ER stress and apoptosis induced by ATO. 
A

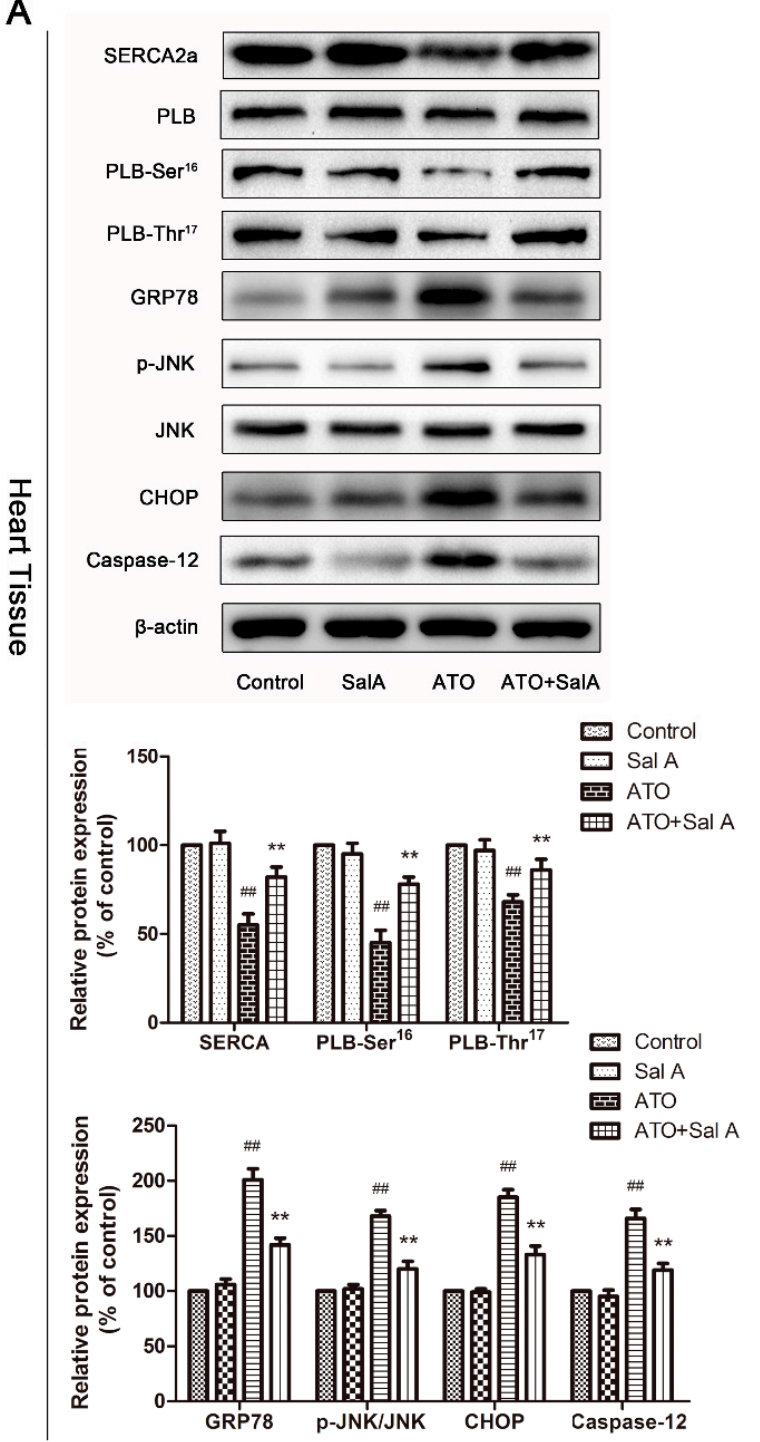

B
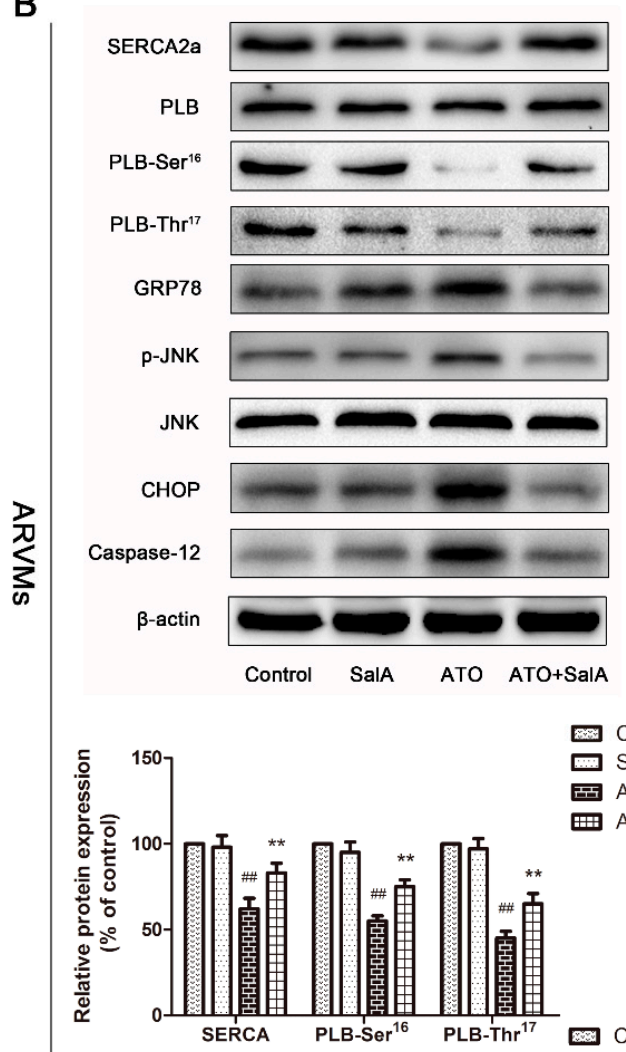

Control

Sal A

臣 ATO

ATO+Sal A

Figure 7. Sal A regulated $\mathrm{Ca}^{2+}$-handling and endoplasmic reticulum (ER) stress-related protein expression after ATO treatment. (A) $\mathrm{Ca}^{2+}$-handling and ER stress-related protein expression in mice heart tissue and (B) in ARVMs. All data are expressed as the mean $\pm \mathrm{SD}$; $\#<0.01$ vs. control, ${ }^{* *} p<0.01$ vs. ATO.

\section{Discussion}

ATO is a potent treatment for APL; however, due to the cardiotoxicity of ATO, many patients with cancer are unable to receive more efficient treatment [18]. Previous research by our team has shown that salvianolic acid B (Sal B) had a protective effect against cardiotoxicity induced by ATO [19]. Subsequently we found that Sal A also suppresses ATO-induced cardiac dysfunction in vivo and in vitro. Importantly, this study has verified that Sal A effectively attenuated cardiac systolic function and intracellular $\mathrm{Ca}^{2+}$ dysfunction induced by ATO. Moreover, SERCA activity in ARVMs and heart tissue increased after the treatment of Sal A compared with the ATO treatment group. The data collected in this study, as well as the data collected in our previous studies, demonstrated that Sal A exerts its cardioprotective effect not only through its antioxidative and anti-apoptotic properties but also through the regulation of calcium homeostasis and ER stress [20].

Oxidative stress is widely considered as one of the main mechanisms underlying the toxicity of ATO [19]. We previously showed that Sal A decreased oxidative stress and intracellular ROS levels, and increased antioxidant enzyme activity against ATO in vitro [11]. In this study, consistent with 
previous studies, Sal A also depressed ATO-induced oxidative stress by increasing the activity of SOD, CAT, GSH-px in vivo. In addition to causing oxidative damage, ATO treatment also caused changes in cardiac function according to the results of echocardiography, and caused myocardial damage by increasing the level of CK, LDH, AST; however, Sal A pretreatment was effective in preventing these alterations and inhibiting cardiotoxicity induced by ATO.

Calcium overload is another primary factor to cause cardiotoxicity by ATO in addition to oxidative stress [11]. $\mathrm{Ca}^{2+}$ is a crucial secondary messenger in ventricular myocytes [21]. $\mathrm{Ca}^{2+}$ homeostasis and $\mathrm{Ca}^{2+}$-mediated signaling are involved in excitation-contraction (EC) coupling and play an important role in normal heart function [22]. ATO treatment leads to a dramatic rise in $\left[\mathrm{Ca}^{2+}\right]_{i}$ due to abnormal $\mathrm{Ca}^{2+}$ handling. Here, the results show that ATO-induced cardiac dysfunction is significantly attenuated by Sal A. Moreover, our results showed that Sal A pretreatment relieved ATO-induced decreases in the decay rates of $\left[\mathrm{Ca}^{2+}\right]_{\mathrm{i}}$ transient, which demonstrated that Sal A increased SERCA activity. SERCA is the critical regulator of $\mathrm{Ca}^{2+}$ homeostasis and contractile activity in the cardiac SR [23]. Our results showed that Sal A preserved SERCA activity in vivo and in vitro and increased SR $\mathrm{Ca}^{2+}$ content, which explains how Sal A-maintained $\left[\mathrm{Ca}^{2+}\right]_{i}$ homeostasis. In addition, PLB, as an SR membrane protein, can regulate SERCA function, and Ser16 and Thr17 are its phosphorylation sites [24]. SERCA activity is restrained by dephosphorylated PLB, but is recovered by phosphorylated PLB. Sal A upregulated ATO-mediated decreases in the expression of SERCA and p-PLB in ARVMs and heart tissue. Consequently, ATO-induced $\mathrm{Ca}^{2+}$ homeostasis imbalance was alleviated after Sal A treatment by adjusting SERCA activity and expression.

The ER or SR in cardiomyocytes play a critical role in protein synthesis, protein folding and transporting, cellular responses to stress, and the change of $\mathrm{Ca}^{2+}$ levels [24]. Firstly, ER transmembrane sensors monitor the unfolded proteins' accumulation, and activate relative pathways to deal with the unfolded and/or misfolded proteins [25]. For example, GRP78 oligomerizes unfolded proteins and disposes them [26]. However, prolonged or severe ER stress will lead to the apoptosis signaling pathway. It is reported that CHOP is a crucial pro-apoptotic transcription factor in ER-mediated apoptosis pathways. In addition, phosphorylated JNK and activated Caspase-12 are also vital parts in this process $[27,28]$. ATO treatment induces $\mathrm{Ca}^{2+}$ overload and calcium homeostasis imbalances, resulting in ER stress [28]. In this study, we found that ATO upregulated the expression of GRP78, JNK, CHOP and caspase-12, which were ER stress- and apoptosis-related proteins, and that Sal A treatment significantly attenuated these increases. These findings proved that ATO induces ER stress and, then, myocardial cell apoptosis. In addition, Sal A reversed ATO-induced structural and functional abnormalities in ARVMs and mice heart tissue, suggesting that the cardioprotective effects of Sal A against ATO may be related to the inhibition of ER stress.

In summary, Sal A suppresses ATO-induced cardiac dysfunction in vivo and in vitro by decreasing cardiac enzymes levels, increasing antioxidant enzyme activities, maintaining calcium homeostasis and inhibiting endoplasmic reticulum stress. Therefore, all findings serve as evidence showing that Sal A has cardioprotective effects against ATO-induced cardiotoxicity.

\section{Materials and Methods}

\subsection{Materials and Animal Treatment}

Sal A (content $\geq 98 \%$ ) was obtained from Shanghai Winherb Medical S\&T Development Co., Ltd. (Shanghai, China). ATO was obtained from Harbin YI-DA Pharmaceutical Ltd. (Harbin, China).

Male BALB/c mice (18 to $20 \mathrm{~g}$ ) and male Sprague-Dawley rats (180-200 g) were bought from Vital River Laboratories, Beijing, China. The protocol was approved by the local animal committee. All procedures and interventions were approved by the Institutional Animal Use and Care Committee (registration number: \#IMPLAD2016030715). Sixty mice were randomly divided into 4 groups as following: (a) a control group (administered $10 \mathrm{~mL} / \mathrm{kg}$ /day saline by intraperitoneal injection $1 \mathrm{~h}$ before $10 \mathrm{~mL} / \mathrm{kg} /$ day saline by tail vein injection), (b) a Sal A group (administered $3 \mathrm{mg} / \mathrm{kg} /$ day Sal A 
by intraperitoneal injection $1 \mathrm{~h}$ before $10 \mathrm{~mL} / \mathrm{kg} /$ day saline by tail vein injection), (c) an ATO group (administered $10 \mathrm{~mL} / \mathrm{kg} /$ day saline by intraperitoneal injection $1 \mathrm{~h}$ before $2 \mathrm{mg} / \mathrm{kg} /$ day ATO by tail vein injection), and (d) an ATO+Sal A group (administered $3 \mathrm{mg} / \mathrm{kg} /$ day Sal A by intraperitoneal injection $1 \mathrm{~h}$ before $2 \mathrm{mg} / \mathrm{kg}$ /day ATO by tail vein injection). Two weeks of administration was implemented in the study.

\subsection{Echocardiographic Measurements}

Echocardiography was used to analyze Cardiac function about $24 \mathrm{~h}$ after last drug treatment. The mice were anesthetized using 1.5-2\% isoflurane, and the Vevo 770 micro-ultrasound system (VisualSonics, Toronto, ON, Canada) was used to detect and analyze M-mode ultrasound images, and the change of ejection fraction (EF), fractional shortening (FS), left ventricular internal diameter in diastole (LVIDd) and left ventricular internal diameter in systole (LVIDs).

\subsection{Heart Histopathological Measurements}

After the detection of echocardiography, the mice heart was trimmed and embedded in paraffin blocks after fixation with $4 \%$ paraformaldehyde. The hearts were sliced and then stained with hematoxylin and eosin (HE). The images were obtained by a light microscope (CKX41, 170 Olympus, Tokyo, Japan).

\subsection{Serum Analysis of LDH, CK, AST, GSH-PX, CAT, and SOD}

After the detection of echocardiography, blood samples were collected from the fundus vein using a capillary tube while the animals were under anesthesia. After at least $2 \mathrm{~h}$ standing, the serums were obtained by centrifuging at $3000 \mathrm{rpm}$ for $15 \mathrm{~min}$. The activity levels of LDH, CK, AST, GSH-PX, CAT, and SOD in serum were detected using commercially available kits purchased from the Jiancheng Bioengineering Institute (Nanjing, China), according to the manufacturer's instructions.

\subsection{Isolation of Adult Rat Ventricular Myocytes (ARVMs)}

ARVMs were isolated using the enzymolysis method, as previously reported [10]. In brief, Sprague-Dawley (SD) rats were anesthetized under pentobarbital sodium (140 mg/ $\mathrm{kg}$ ip) before opening the chest, and the hearts were excised quickly and then suspended on a Langendorff perfusion apparatus. Then the hearts were successively perfused with solution A (HEPES, 10; $\mathrm{NaCl}, 137$; glucose, $10 ; \mathrm{KCl}, 5.4 ; \mathrm{MgCl}_{2}, 1.2 ;$ and $\mathrm{CaCl}_{2}, 1.2$ [in $\mathrm{mM}$ ]) for $2 \mathrm{~min}$, solution $\mathrm{B}$ (HEPES, 10; $\mathrm{NaCl}, 137$; glucose, $10 ; \mathrm{KCl}, 5.4$ and $\mathrm{MgCl}_{2}, 1.2$ [in $\mathrm{mM}$ ]) for $5 \mathrm{~min}$, and solution $\mathrm{B}$ with collagenase type II for 10-15 min. After perfusion, the single cell was obtained by filtering digested heart tissues using a 300-mm nylon mesh. The cell suspension was deposited 3 times with solution A to progressively increase the extracellular $\mathrm{Ca}^{2+}$ concentration to $1.2 \mathrm{mM}$. Suspensions with a cell viability rate over $85 \%$ were used in this study, of which rod-shaped ARVMs with prominent sarcomere were contained.

\subsection{Measurement of Sarcomere Shortening and $\mathrm{Ca}^{2+}$ Transients in ARVMs}

Our experiment used video-based sarcomere contractility and calcium recording module in a SoftEdge MyoCam System (IonOptix Corporation, Milton, MA, USA) to assess sarcomere shortening and $\mathrm{Ca}^{2+}$ transients, as previously reported [11]. Firstly, isolated ARVMs were incubated with Fura-2/AM $(2 \mu \mathrm{M})$ for $15 \mathrm{~min}$, then the cells were washed twice with solution A. Subsequently, the ARVMs were placed in a Warner chamber mounted on the stage of an inverted microscope (Olympus, IX-70) and perfused with different solutions at a rate of $1.5 \mathrm{~mL} / \mathrm{min}$. The experiment was grouped as follows: (a) control group: solution A for $30 \mathrm{~min}$; (b) Sal A group: solution A with $1 \mu \mathrm{M}$ Sal A for 10 min; (c) ATO group: solution A with $100 \mu \mathrm{M}$ ATO for 20 min; and (d) ATO+Sal A group: solution A with $100 \mu \mathrm{M}$ ATO for 20 min after solution A with $1 \mu \mathrm{M}$ Sal A for $10 \mathrm{~min}$. The ARVMs were allowed to stabilize for approximately $10 \mathrm{~min}$ before being analyzed. In our studies, 30-40 cells from 
5 rats per group were obtained. The recording and analysis of data were conducted using IonWizard software (version 6.2.0.59, Milton, MA, USA).

\subsection{SERCA Activity Detection}

SERCA activity of ARVMs and mice heart tissue were detected respectively. For ARVMs, the rod-shaped cardiomyocytes with prominent sarcomere were treated as followed: (a) control group: solution A for $30 \mathrm{~min}$; (b) Sal A group: solution A with $1 \mu \mathrm{M}$ Sal A for $10 \mathrm{~min}$; (c) ATO group: solution A with $100 \mu \mathrm{M}$ ATO for $20 \mathrm{~min}$; and (d) ATO+Sal A group: solution A with $100 \mu \mathrm{M}$ ATO for 20 min after solution A with $1 \mu \mathrm{M}$ Sal A for $10 \mathrm{~min}$. After all treatment, ARVMs were added to PBS buffer solution and then broken using ultrasound. Cell suspension was centrifuged for $10 \mathrm{~min}$ at $3500 \mathrm{rpm}$ and the supernatant was used to detect the SERCA activity. For mice heart tissue, the tissue of 4 groups was added to $10 \mathrm{~mL} / \mathrm{g}$ saline, and then fully homogenized. Tissue suspension was centrifuged for $10 \mathrm{~min}$ at $3500 \mathrm{rpm}$ and the supernatant was used to detect the SERCA activity. SERCA activity was measured using a commercially available kit (CAT\#A070, Nanjing Jiancheng Bioengineering Institute, Nanjing, China). The specific operation was completed according to the manufacturer's instructions.

\subsection{Western Blot Analysis}

After exposure to the group-specific solutions described in 4.1 and 4.6, the proteins of the mice heart tissue homogenates and ARVMs were obtained with the tissue or cell protein extraction reagent, and were determined by a BCA kit (Pierce Corporation, Rockford, IL, USA). Approximately 30 to $50 \mu \mathrm{g}$ of protein was loaded onto $10 \%$ or $12 \%$ sodium dodecyl sulfate (SDS) polyacrylamide gel and then transferred to nitrocellulose membranes, which were incubated overnight at $4{ }^{\circ} \mathrm{C}$ with primary antibodies including: Santa Cruz: PLB (sc-21923), PLB-Ser16 (sc-12963), PLB-Thr17 (sc-17024), p-JNK (Thr183/Tyr185, sc-293136), and JNK (sc-7345); Abcam: SERCA (ab2861), caspase-12 (ab18766), GRP78 (ab21685) and CHOP (ab11419). Then the membranes were washed and incubated with secondary antibodies (CWbiotech Beijing, China) for $2 \mathrm{~h}$ at room temperature. The immunoblots were developed using an electrochemiluminescence (ECL) kit, and then scanned; densitometric analysis was performed using Gel Pro software (Media Cybernetics, Rockville, MD, USA).

\subsection{Statistical Analysis}

All data are presented as means \pm standard deviation (SD) from at least 3 independent experiments. Comparisons between different groups were performed using one-way ANOVA followed by Tukey's test with GraphPad Prism 5.0 software (SPAA Inc., Chicago, IL, USA), and graphical presentation of data was also undertaken with GraphPad Prism. A $p$-value less than 0.05 was considered statistically significant.

\section{Conclusions}

Sal A treatment before ATO suppressed $\mathrm{Ca}^{2+}$ overload and improved SERCA activity and expression, thereby alleviating ATO-induced calcium homeostasis imbalances. In addition, Sal A inhibited ATO-induced ER stress by downregulating GRP78, JNK, CHOP and caspase-12. Our findings suggest that Sal A protects against ATO-induced cardiac injury and improves myocardial performance. The cardioprotective effect seems to be due largely to the maintenance of calcium homeostasis and the attenuation of ER stress-associated apoptosis in vivo and in vitro. These results demonstrated that Sal A prevents ATO-induced cardiotoxicity, which has significant implications for clinical application. However, our study is still in its initial stages, and the exact mechanisms underlying the cardioprotective activity of Sal A require further study.

Supplementary Materials: The following are available online at http:/ / www.mdpi.com/1420-3049/24/3/543/s1, Figure S1: Sal A regulated intracellular $\mathrm{Ca}^{2+}$ transients in ARVMs after ATO treatment in dot plots, Figure S2: Representative traces of sarcomere shortening and $\mathrm{Ca}^{2+}$ transient at different groups. 
Author Contributions: Conceptualization, R.W., J.Y., G.S. and X.S.; Data curation, R.W., Y.D. and X.X.; Formal analysis, S.W. and M.W.; Investigation, S.W. and T.Y.; Methodology, R.W. and J.Z.; Project administration, J.Z.; Resources, T.Y. and Y.D.; Software, J.Z.; Supervision, M.W.; Validation, J.Y., G.S. and X.S.; Visualization, J.Y.; Writing - original draft, R.W.; Writing - review \& editing, G.S. and X.S.

Funding: This research was funded by Major Scientific and Technological Special Project for Significant New Drugs Formulation (Grant No. 2017ZX09301069), the Special Research Project for TCM (Grant No. 201507004), and the National Science and Technology Major Project (Grant No. 2015ZX09501004-001-003).

Conflicts of Interest: The authors declare no conflict of interest.

\section{References}

1. Zhu, J.; Chen, Z.; Lallemand-Breitenbach, V.; de The, H. How acute promyelocytic leukaemia revived arsenic. Nat. Rev. Cancer 2002, 2, 705-713. [CrossRef] [PubMed]

2. Shen, Z.X.; Chen, G.Q.; Ni, J.H.; Li, X.S.; Xiong, S.M.; Qiu, Q.Y.; Zhu, J.; Tang, W.; Sun, G.L.; Yang, K.Q.; et al. Use of arsenic trioxide $\left(\mathrm{As}_{2} \mathrm{O}_{3}\right)$ in the treatment of acute promyelocytic leukemia (APL): II. Clinical efficacy and pharmacokinetics in relapsed patients. Blood 1997, 89, 3354-3360. [PubMed]

3. Fox, E.; Razzouk, B.I.; Widemann, B.C.; Xiao, S.; O’Brien, M.; Goodspeed, W.; Reaman, G.H.; Blaney, S.M.; Murgo, A.J.; Balis, F.M.; et al. Phase 1 trial and pharmacokinetic study of arsenic trioxide in children and adolescents with refractory or relapsed acute leukemia, including acute promyelocytic leukemia or lymphoma. Blood 2008, 111, 566-573. [CrossRef] [PubMed]

4. Westervelt, P.; Brown, R.A.; Adkins, D.R.; Khoury, H.; Curtin, P.; Hurd, D.; Luger, S.M.; Ma, M.K.; Ley, T.J.; DiPersio, J.F. Sudden death among patients with acute promyelocytic leukemia treated with arsenic trioxide. Blood 2001, 98, 266-271. [CrossRef] [PubMed]

5. Huang, S.Y.; Chang, C.S.; Tang, J.L.; Tien, H.F.; Kuo, T.L.; Huang, S.F.; Yao, Y.T.; Chou, W.C.; Chung, C.Y.; Wang, C.H.; et al. Acute and chronic arsenic poisoning associated with treatment of acute promyelocytic leukaemia. Br. J. Haematol. 1998, 103, 1092-1095. [CrossRef] [PubMed]

6. Zhao, X.; Feng, T.; Chen, H.; Shan, H.; Zhang, Y.; Lu, Y.; Yang, B. Arsenic trioxide-induced apoptosis in H9c2 cardiomyocytes: Implications in cardiotoxicity. Basic Clin. Pharmacol. Toxicol. 2008, 102, 419-425. [CrossRef] [PubMed]

7. Vineetha, V.P.; Girija, S.; Soumya, R.S.; Raghu, K.G. Polyphenol-rich apple (Malus domestica L.) peel extract attenuates arsenic trioxide induced cardiotoxicity in H9c2 cells via its antioxidant activity. Food Funct. 2014, 5, 502-511. [CrossRef]

8. Zima, A.V.; Blatter, L.A. Redox regulation of cardiac calcium channels and transporters. Cardiovasc. Res. 2006, 71, 310-321. [CrossRef]

9. Wang, C.; Liu, N.; Luan, R.; Li, Y.; Wang, D.; Zou, W.; Xing, Y.; Tao, L.; Cao, F.; Wang, H. Apelin protects sarcoplasmic reticulum function and cardiac performance in ischaemia-reperfusion by attenuating oxidation of sarcoplasmic reticulum $\mathrm{Ca}^{2+}$-ATPase and ryanodine receptor. Cardiovasc. Res. 2013, 100, 114-124. [CrossRef]

10. Zhang, J.Y.; Sun, G.B.; Wang, M.; Liao, P.; Du, Y.Y.; Yang, K.; Sun, X.B. Arsenic trioxide triggered calcium homeostasis imbalance and induced endoplasmic reticulum stress-mediated apoptosis in adult rat ventricular myocytes. Toxicol. Res. 2016, 5, 682-688. [CrossRef]

11. Zhang, J.Y.; Sun, G.B.; Luo, Y.; Wang, M.; Wang, W.; Du, Y.Y.; Yu, Y.L.; Sun, X.B. Salvianolic acid a protects $\mathrm{H} 9 \mathrm{c} 2$ cells from arsenic trioxide-induced injury via inhibition of the mapk signaling pathway. Cell. Physiol. Biochem. 2017, 41, 1957-1969. [CrossRef] [PubMed]

12. Wang, B.; Liu, J.X.; Meng, H.X.; Lin, C.R. Blocking effect of salvianolic acid A on calcium channels in isolated rat ventricular myocytes. Chin. J. Integr. Med. 2012, 18, 366-370. [CrossRef] [PubMed]

13. Yan, X.; Jiang, Z.; Bi, L.; Yang, Y.; Chen, W. Salvianolic acid A attenuates TNF-alpha- and D-GalN-induced ER stress-mediated and mitochondrial-dependent apoptosis by modulating Bax/Bcl-2 ratio and calcium release in hepatocyte $\mathrm{LO}_{2}$ cells. Naunyn-Schmiedeberg's Arch. Pharmacol. 2015, 388, 817-830. [CrossRef] [PubMed]

14. Rajadurai, M.; Stanely, M.P.P. Preventive effect of naringin on cardiac markers, electrocardiographic patterns and lysosomal hydrolases in normal and isoproterenol-induced myocardial infarction in Wistar rats. Toxicology 2007, 230, 178-188. [CrossRef] [PubMed]

15. Hagemann, D.; Xiao, R.P. Dual site phospholamban phosphorylation and its physiological relevance in the heart. Trends Cardiovasc. Med. 2002, 12, 51-56. [CrossRef] 
16. Kranias, E.G.; Hajjar, R.J. Modulation of cardiac contractility by the phospholamban/SERCA2a regulatome. Circ. Res. 2012, 110, 1646-1660. [CrossRef] [PubMed]

17. Hetz, C. The unfolded protein response: Controlling cell fate decisions under ER stress and beyond. Nat. Rev. Mol. Cell Biol. 2012, 13, 89-102. [CrossRef] [PubMed]

18. Wang, M.; Sun, G.B.; Sun, X.; Wang, H.W.; Meng, X.B.; Qin, M.; Sun, J.; Luo, Y.; Sun, X.B. Cardioprotective effect of salvianolic acid B against arsenic trioxide-induced injury in cardiac H9c2 cells via the PI3K/Akt signal pathway. Toxicol. Lett. 2013, 216, 100-107. [CrossRef]

19. Zhang, J.Y.; Zhang, B.; Wang, M.; Wang, W.; Liao, P.; Sun, G.B.; Sun, X.B. Calcium homeostasis and endoplasmic reticulum stress are involved in Salvianolic acid B-offered protection against cardiac toxicity of arsenic trioxide. Oncotarget 2017, 8, 97384-97393. [CrossRef]

20. Feng, S.; Geng, J.; Sun, R.; Huang, J.; Tan, Z.; Yan, C.X.; Wang, G. Protective effect of salvianolic acid a on brain endothelial cells after treatment with deprivation and reperfusion of oxygen-glucose. Chin. Herb. Med. 2017, 9, 335-343. [CrossRef]

21. Bernardi, P.; Rasola, A. Calcium and cell death: The mitochondrial connection. Subcell Biochem. 2007, 45, 481-506. [PubMed]

22. Bers, D.M. Calcium fluxes involved in control of cardiac myocyte contraction. Circ. Res. 2000, 87, $275-281$. [CrossRef] [PubMed]

23. Lipskaia, L.; Keuylian, Z.; Blirando, K.; Mougenot, N.; Jacquet, A.; Rouxel, C.; Sghairi, H.; Elaib, Z.; Blaise, R.; Adnot, S.; et al. Expression of sarco (endo) plasmic reticulum calcium ATPase (SERCA) system in normal mouse cardiovascular tissues, heart failure and atherosclerosis. Biochim. Biophys. Acta 2014, 1843, 2705-2718. [CrossRef] [PubMed]

24. Dong, S.; Teng, Z.; Lu, F.H.; Zhao, Y.J.; Li, H.; Ren, H.; Chen, H.; Pan, Z.W.; Lv, Y.J.; Yang, B.F.; et al. Post-conditioning protects cardiomyocytes from apoptosis via PKC(epsilon)-interacting with calcium-sensing receptors to inhibit endo(sarco)plasmic reticulum-mitochondria crosstalk. Mol. Cell. Biochem. 2010, 341, 195-206. [CrossRef] [PubMed]

25. Gorman, A.M.; Healy, S.J.; Jager, R.; Samali, A. Stress management at the ER: Regulators of ER stress-induced apoptosis. Pharmacol. Ther. 2012, 134, 306-316. [CrossRef] [PubMed]

26. Kadowaki, H.; Nishitoh, H.; Ichijo, H. Survival and apoptosis signals in ER stress: The role of protein kinases. J. Chem. Neuroanat. 2004, 28, 93-100. [CrossRef] [PubMed]

27. Kim, I.; Xu, W.; Reed, J.C. Cell death and endoplasmic reticulum stress: Disease relevance and therapeutic opportunities. Nat. Rev. Drug Discov. 2008, 7, 1013-1030. [CrossRef]

28. Xu, C.; Bailly-Maitre, B.; Reed, J.C. Endoplasmic reticulum stress: Cell life and death decisions. J. Clin. Investig. 2005, 115, 2656-2664. [CrossRef]

Sample Availability: Samples of the compounds are not available from the authors.

(C) 2019 by the authors. Licensee MDPI, Basel, Switzerland. This article is an open access article distributed under the terms and conditions of the Creative Commons Attribution (CC BY) license (http://creativecommons.org/licenses/by/4.0/). 